\title{
Regulating Substances of Very High Concern
}

Which criteria should be used to regulate substances of very high concern in accordance with Article 57(f) of the REACH regulation? This question was discussed by a group of experts at a workshop in Berlin.

O ne of the key points of the EU Regulation concerning the Registration, Evaluation, Authorisation and Restriction of Chemicals (REACH) is the definition of substances of very high concern (SVHC). These include substances that are carcinogenic, mutagenic or toxic to reproduction. In addition, according to Article 57(f) of the regulation, other substances with different properties which "give rise to an equivalent level of concern" can also be identified as SVHC. However, the REACH regulation does not define any specific criteria for these substances. For this reason, the German Federal Institute for Occupational Safety and Health (BAuA) and the German Federal Institute for Risk Assessment (BfR) held a one-day workshop on the subject in Berlin, at which the possible criteria for these additional SVHC that "give rise to an equivalent level of concern" were discussed. Entitled "REACH Article 57(f): Non-Endocrine Disrupting Hu- man Health Hazards Leading to SVHC Identification", the workshop attracted experts from German and European public bodies, the chemical industry and non-governmental organisations (NGOs), who considered how Article 57(f) should be applied in practice.

\section{Standardised concept}

The experts at the workshop agreed that a standardised concept for dealing with Article 57(f) would be very helpful. For example, in their opinion substances that can cause allergic reactions when they come into contact with the respiratory system meet the requirements of Article 57(f) and can therefore be regarded in principle as substances of very high concern. In addition, the representatives of the BAuA and the BfR explained in their presentations that under certain circumstances substances which can cause serious organ damage were also possible candidates for the status of SVHC.
Chemicals which cause only minor damage to health or which by their nature require effective risk management, such as highly caustic substances, should not generally be regarded as SVHC.

During the course of the debates at the workshop, it became clear that in many areas there was a need for further discussions between the authorities and the stakeholders from industry and from NGOs. However, the talks held at the workshop involving representatives of different interest groups are the first successful step towards establishing a uniform approach. The BAuA and the BfR came to the conclusion that agreement on a standardised concept would not only result in greater transparency when working with Article 57(f), but would also allow for effective risk management in the case of hazardous substances that have not yet been adequately regulated.

For more information: www.baua.de

\section{BASF Invests in Production of Hexanediol}

B ASF will increase its annual global capacity for manufacturing the chemical intermediate 1,6-hexanediol (HDO) by more than 20 percent to more than 50,000 tonnes per annum by 2014. For this purpose, the company will further optimise its production processes, carry out various infrastructure projects and enhance its logistical processes. BASF will invest more than 30 million euros. BASF operates HDO production facilities at its Ver- bund sites in Freeport, Texas, and Ludwigshafen, Germany.

"By increasing our capacity and further optimising our operations, we are responding to the growing demand for innovative high-performance formulations," said Sanjeev Gandhi, President, BASF Intermediates division, and added, "by aligning with the growth of our customers and ensuring the availability of high-quality HDO, we continue to serve our global customers as a reliable partner."
The intermediate is used to manufacture industrial coatings, including lower volatile organic compound formulations, polyurethane plastics, adhesives and cosmetics. HDO also serves as a reactive thinner in the formulation of epoxy systems, which are used for the efficient production of rotor blades for modern wind turbines as well as construction components for automotive lightweight applications. 